\title{
Kazaklara Türkçe Öğretimi ve Söz Edimsel Bir Karşılaştırma*
}

\author{
Mustafa Durmuş ș $^{*}$ \\ Alp Kaan Kılınç ${ }^{* * *}$
}

\begin{abstract}
$0 \ddot{z}$
$\mathrm{Bu}$ çalışmada karşılaştırmalı öğretim yaklaşımı (comparative teaching approach), lehçeler arası öğretim için yararlanılabilecek bir yaklaşım olarak önerilmektedir. Bu yaklaşımda, hedef dile dair izole edilmiş yepyeni dilsel veya dil dışı yapılar inşaa etmenin yanı sıra öğrenicilerin mevcut bilgilerinden yola çıkmanın bazı yararları olacağı değerlendirilmektedir: örneğin, öğrenmeyi kolaylaştırabilir, hata analizinde yararlı olabilir ve öte yandan hedef dile ve o dilin de içerisinde yer aldığı kültüre dair daha fazla farkındalık geliştirebilir. Ana dilinin hedef dili öğrenme sürecinde engelleyici etkisi olup olmadığı sorunsalıyla ilgili olumsuzlayıcı görüşler karşısında, bu çalışmada, aslında öğrenicilerin ana dilinin yok sayılması yerine yukarıdaki olumlu etkilerinin yanı sıra stratejik kullanılabilmesi durumunda hedef dilin önemli bir destek unsuru olabileceği görüşü savunulmaktadır. Kazakça ve Türkçe konuşurlarının dilsel ve kültürel unsurları bakımından farklılıklarına ve ortaklıklarına işaret edilen makalede, sözel davranışlar bakımından da bir karşılaştırma örneği sunulmuş; 20 Türk ve 20 Kazak üniversite hazırlık sınıfı öğrencisi ile gerçekleştirilen yazılı çalışmanın sonuçları istek (rica) söz edim tercihleriyle ilgili olarak karşılaştırılmıştır. Sonuç olarak, Türk ve Kazak öğrencilerin istek (rica) strateji tercihlerinde benzerlikler görüldüğü gibi, başta emir (imperatives) ve istek ifadeleri (want statements) kullanımları olmak üzere çeşitli farklılıklar da tespit edilmiştir.
\end{abstract}

\section{Anahtar Kelimeler}

Kazaklara Türkçe öğretimi, yabancı dil olarak Türkçe öğretimi, karşılaştırmalı yaklaşım, istek (rica) söz edimi.

\footnotetext{
Geliş Tarihi: 16 Ekim 2019 - Kabul Tarihi: 06 Kasım 2019

Bu makaleyi şu şekilde kaynak gösterebilirsiniz:

Durmuş, Mustafa, ve Alp Kaan Kılınç. “Kazaklara Türkçe Öğretimi ve Söz Edimsel Bir Karşılaştırma.” bilig, no. 97, 2021, ss. 1-28.

** Prof. Dr., Hacettepe Üniversitesi, Türkiyat Araştırmaları Enstitüsü - Ankara/Türkiye ORCID ID: 0000-0002-5337-3113 mustafadurmus@hacettepe.edu.tr

*** Öğr. Gör., Ankara Yıldırım Beyazıt Üniversitesi, Yabancı Diller Yüksekokulu - Ankara/Türkiye ORCID ID: 0000-0002-8709-9554 alpkaankilincc@gmail.com
} 


\section{Giriş}

İzole edilmiş yepyeni dilsel veya dil dışı yapılar inşaa etmek yerine öğrenicilerin mevcut bilgilerinden yola çıkan karşılaştırmaya dayalı öğretim, bir dilin lehçelerini konuşanların, birbirlerinin dillerini öğrenme sürecinde yararlı olabilecek bir yaklaşımdır. Bu yaklaşımda, bir yandan var olan bilgilerden yola çıkıldığı için öğrenmeyi kolaylaştırabilmek, öte yandan hedef dile ve o dilin de içerisinde yer aldığı kültüre dair daha fazla farkındalık geliştirebilmek mümkün olabilir. Lehçeler arası öğretim için yararlanılabilecek bu karşılaşırımaya dayalı yaklaşımı, Paradowski'nin vurgusuyla, "karşıtlıklara/zitlıklara odaklı" karşıtsal yaklaşım (contrastive approach), karşıtsal analiz (contrastive analysis) veya karşıtsal dilbilim (contrastive linguistic) gibi terimlerle değil, "ortaklıklara veya benzerliklere odaklı” karşılaştırmalı yaklaşım (comparative approach), karşılaşıırmalı analiz (comparative analysis) veya karşılaştırmalı dilbilim (comparative linguistic) gibi terimlerle ifade etmenin öğrenici hatta öğretici güdülenmesi açısından da daha uygun olacağı değerlendirilmektedir.

Aynı ana dili konuşurlarından oluşan sınıflarda, birbirine yakın dillerin, lehçelerin öğretimi için uygun olabileceği değerlendirilen bu karşılaştırmalı analiz yaklaşımıyla ilgili olarak Paradowski, 1970’lere kadar, her şeyden önce ana dilinin hedef dili öğrenme sürecinde engelleyici etkisine ve daha özelde, bu karşıtlı̆ga dayalı bilginin, hedef dili kullanırken yabancı/ ikinci dil öğrenicilerinin "hatalarını" tahmin etmeye yardımcı olacağına inanıldığını belirtmektedir. Bu nedenle karşıtsal analiz, hata analizi ile güçlü bir şekilde ilişkilendirilmiş ve ana dilinin özelliklerine benzerlik gösteren tüm hedef dil hatalarını ana dili girişiminin kanıtı olarak yorumlama eğilimi göstermiştir. Ancak 1970’lerde, davranış̧̧ıların genel olarak öğrenme görüşlerinin popülaritesindeki bir düşüşle örtüşecek şekilde, yabancı/ikinci dil öğreniminin önündeki engelleri öngörme modeli çok basit olarak kabul edilmiş ve ikinci dil edinimi araştırmacıları karşıtsal analizi potansiyel zorluk alanlarını saptamak için bir araç olarak yeniden kullanmış; ve bilişsel bir çerçeve içinde aktarım (transfer) 
kavramını yeniden yerleştirmişlerdir. Nitekim o yıllarda dil pedagojisinde karşıtsal analizden elde edilen bilgileri kullanma gerekçesi, aktarım ve girişim (interference) kavramlarına dayanmaktadır. Ayrıca, vurgu, yabancı dil öğrenimini engelleyici etkenlerden (yani ana dili ile hedef dil arasındaki zıtlıklardan) yabancı dil öğrenimini destekleyebilecek ve kolaylaştırabilecek etkenlere (yani, her iki dil arasındaki benzerliklere) kaymaya başlamışıı (2-3). Bu nedenle de Paradowski, karşıtsal dilbilim yerine uygulamal karşılaştırmalı dilbilim terimini kullanmayı tercih etmektedir.

Koneva da karşılaştırmaya dayalı bir öğretim için veri oluşturabilecek bilgiler sunarken, Sural'ın, düşünce biçimini değiştirmenin ve dünya görüşünü garip ve sıradışı bir örüntüye göre yeniden inşa etmenin gerekliliğinin yabanc1/ikinci dil edinimindeki temel psikolojik güçlüklerden biri olduğu görüşüyle birlikte; Vinogradov'un, benzer dillerin karşılaştırmalı ve tarihî bir öğreniminin yanı sıra, farklı sistemlere ait dilleri karşılaştırmanın mümkün, hatta gerekli olduğu değerlendirmesini aktarmaktadır (320).

\section{Kazakça ve Türkçe Arasındaki Dilbilgisel Farklılaşma Örnekleri}

$\mathrm{Bu}$ bağlamda, dil öğrenenlerde dilbilgisel farkındalık geliştirmenin ve ortaklıklara/benzerliklere dayalı öğretimin yollarından biri öğrenicilerin ve hedef dilin dilbilgisel özelliklerinin karşılaştırılarak sunulmasıdır. Öğrenicinin ana dili ile hedef dil arasında sesbilimsel (phonetic), sesbilgisel (phonologic), biçimbilgisel (morphologic), sözdizimsel (syntactic), sözcüksel (lexic) karşılaştırmalar öğrenicilerde hedef dile dair yapısal ve kullanımsal farkındalığı geliştirme olanağı sunabilir. Bu dilbilgisel unsurlara dair farkındalık geliştikçe, aşağıda ele alınan bir dizi yapısal farklılıktan kaynaklı yazılı ve sözlü hata da giderilebilecektir. Kazakça konuşurlarına karşılaştırmalı yaklaşıma dayalı olarak Türkçe öğretecek kişinin, ortaklıklara dair ön bilgi oluştururken takip edeceği yollardan biri şüphesiz farklılıkları tanımak olabilir.

Türk dili ailesinin üyeleri için ortak yapısal özellikler listelenebilirken (Johanson (37-46), bu ortak özellikleri 46 madde hâlinde listeler.) Erdem'in 
belirttiği gibi, Türk lehçelerindeki ünlü uyumları bazı açılardan Türkiye Türkçesinde görülen düzlük-yuvarlaklık uyumundan farklılaşır. Özellikle düzlük-yuvarlaklık uyumunun zayıf olduğu veya Kazakçadaki gibi Türkiye Türkçesinden daha ileri olduğu durumlar oldukça fazladır. Örneğin Kazakça (ayrıca Balkarca, Karakalpakça) gibi Kıpçak dillerinin bazılarında geniş ünlüler bile yuvarlaklaşabilmektedir (72).

Ayrıca, Kazakçadaki düzenli ses değişmeleri dolayısıyla, Kazakça ile Türkçe arasında eşsesli kelimeler ortaya çıkmaktadır. Kazakçadaki ş $>s$ ses değişmesinin Kazakça ile Türkçe arasında ortaya çıkardığı eşsesli sözcük örneklerinden bazıları şöyledir:

\begin{tabular}{|c|c|c|c|}
\hline Kz. as "yemek" & - Tr. as- & Kz. kas "kaş" & - Tr. kas \\
\hline Kz. bas "baş" & - Tr. bas- & Kz. kus "kuş" & - Tr. kus- \\
\hline Kz. es- "eğir-" & - Tr. es- & Kz. pis- "pismek" & $\sim$ Tr. pis \\
\hline Kz. is "iş" $b$ & - Tr. is & Kz. tas "taş" & - Tr. tas \\
\hline Kz. iste- "çalış-" & ～Tr. iste- & Kz. tös "döş" & - Tr. tös \\
\hline
\end{tabular}

Kazakçadaki ç > şs ses değişmesinin Kazakça ile Türkçe arasında ortaya çıkardığı eşsesli sözcük örneklerinden bazıları şöyledir:

Kz. aş- "açmak" - Tr. aş(-) "aş, aş-" Kz. kaş- "kaç-" -Tr. kaş "kaş"

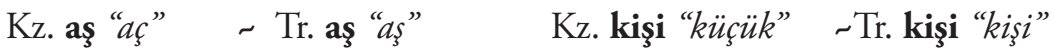

Kz. aşık "açık" - Tr. aşık "aşık kemiğì"Kz. kuşak "kucak" - Tr. kuşak "kuşak"

Kz. iş "iç" - Tr. iş "i̧̧̧" Kz. piş- "biçmek" - Tr. piş- "piş-"

Kz. iş- "iç_" - Tr. iş "iş" Kz. şak "dönem" - Tr. şak "ses taklidi" (Karini, 2013)

Sarsenbekova, Kazakça ile Türkçe arasındaki yalancı eş değer sözcükleri belirlemek amacıyla hazırladığı çalışmada, 342'si (\% 83) tam yalancı eş değer, 72'si (\% 17) ise kısmî yalancı eş değer toplam 414 sözcük belirlemiştir. $\mathrm{Bu}$ verilere göre, yalancı eş değerlik gösteren sözcüklerin büyük bir kısmı 
iki dil arasında anlamları hiç örtüşmeyen tam yalancı eş değer sözcüklerdir. Belirlenen bu 414 yalancı eş değer sözcük arasında Eş Sesli Sözcüklerden Oluşan Yalancı Eş Değerlerin toplam sayısı 253 'ür. Ses değişimleri yoluyla oluşan yalancı eş değer sözcüklerin toplam sayısı ise 161'dir (121-3).

Kazakça-Türkçe arasındaki 414 yalancı eş değer sözcüğün düzeylere göre dağılımına dair öneri niteliğinde sunduğu listede Sarsenbekova, Güncel Türkçe Sözlükteki madde başı sözcükleri incelenmiş ve bu sözcüklerin büyük bir kısmının temel düzeye ait olduğunu ifade etmiştir. Belirlenen yalancı eş değer sözcüklerden 111'nin (ara, ata, baba, banka, bay, cuma, dil, doğa, kapal, kaza, kişi, kısa, kol, köşe, muz, nar, ön, para, pazar, takım, sanat gibi adların yanı sıra alış-, dur-, düşün-, iste-, koş-, tara- gibi filler) A1'de, 52'sinin (bayağı, çalgr, damak, hat, kap, kısım, neşe, sulu, ten gibi adların yanı sıra gelişs-, öt-, parlagibi filler) A2'de yer alabileceğini belirtmektedir. Yine, 55 sözcüğün (aman, cihaz, eser, ezgi, keşke, tel, yazım gibi adların yanı sıra aktar-, darıl-, geçir-, götür-, onayla-, rastla- gibi filler) B1 düzeyinde, 48 sözcüğün (algr, akın, azar, bedel, biliş, kalkan, nakil, odak adların yanı sıra basıl-, sarsıl-, sindir-gibi filler) B2'de, 28 sözcügün (azil, hor, kor, payda, sur, zat gibi adların yanı sıra bilefili) C1 düzeyinde ve son olarak 65 sözcüğün de (azamet, bostan, kesir, kursak, niyaz, ören, sapa, uşak gibi adların yanı sıra tın-, ula- filleri) C2 düzeyinde geçebileceğini değerlendirmektedir (116-120).

Uğurlu, "kelime eş değerliği" terimiyle, iki ayrı lehçede bulunan kelimelerin birbirlerine "kavram alanı" bakımından denk olma durumunun ifade edildiğini; Türk lehçelerinin kelime hazinelerinin tam örtüşmemesinin, kelime eş değerliği konusunun önemini arttırdığını; Türk lehçeleri arasında yapılacak aktarmaların başarılı olabilmesinin de, "kaynak lehçe"deki bir kelimenin "hedef lehçe"deki eş değerinin bilinmesi ve kullanılmasına bağlı olduğunu; kelime eş değerliği yönünden; "bire bir", "bire çok" ve "bire hiç" durumu söz konusuyken, başarılı bir aktarma için bilhassa, bir kelimeye birden fazla kelimenin eş değer olduğu duruma özen göstermek gerektiğini; zira böyle kelimeleri aktarırken hata yapma ihtimalinin yükseldiğini belirtmektedir (29). Türk lehçeleri arasında eş değer olan 
sözcüklerin pek azının; ses, anlam vb. yönlerden her bir Türk lehçesinde “aynı” olabileceği tespitini Ercilasun da ortaya koymaktadır (90). Uğurlu, yukarıdaki açıklamaları ile birlikte ayrıca, eş değer kelimelerin pek çoğunun, aynı kaynaktan geldikleri hâlde zaman içinde belli ses değişikliklerine uğradıklarını; anlam yönünden ise, kelimelere göre benzerliğin derecesinin değiştiğini; benzerlik oranının da, bilhassa, sayılar (Örn. Ttü. beş 三 Kaz. Bes $\equiv$ Az. beş $\equiv$ Başk. biş $\equiv$ Kırg. beş $\equiv$ Özb. beş $\equiv$ Tat. biş $\equiv$ Türkm. beeş $\equiv$ Uyg. bäs) gibi "sınırlı" anlamı olanlar arasında yüksek olup kavram alanlarının tam örtüşmeye çok yakın olduğunu ortaya koymaktadır. Bunun yanı sıra Uğurlu’ya göre, "at" gibi birçok Türk lehçesinde ses bakımından aynı olan (Örn. Ttü. $a t \equiv$ Kaz. $a t \equiv$ Az. $a t \equiv$ Başk. at $\equiv$ Kırg. $a t \equiv$ Özb. $a t \equiv$ Tat. $a t \equiv$ Türkm. $a t \equiv$ Uyg. at) sözcükler arasında kavram, çağrışım, kullanım sıklığı vb. yönlerden tam değil, ancak kabul edilebilir bir örtüşme söz konusu olabilirken, bir örnek olarak, bir Türkiyelinin at’tan anladığı ile, bu hayvanın etini yiyen, sütünü içen bir Kazak veya Kırgızın anladığı aynı olmayıp, bir Kazak için bu kavramın çağrışımı kazı, en lezzetli yemek iken, bir Türkiyeli için herhâlde olumsuz bir şeydir. Yine, "atı alan Üsküdar'ı geçti” gibi bir metin üretimi, sadece Türkiye'de konuşulan Türkçe için söz konusudur (29). Bunlardan başka, çokluk eki -lAr'ın başka alt biçimbirimleriyle Kazakçada -LAr biçimindeki kullanımı, Kazakçanın ses uyumlarından kaynaklanmaktadır.

İlgi hâli ekinin Türkçede ünlü ile başlayan $(+\mathrm{Xn})$ ve ünsüz ile başlayan $(+n X n)$ biçimlerine karşllık Kazakçadaki ünsüz ile başlayan biçimler, bu lehçenin konuşurlarının mevcut ana dili özelliklerini Türkçe öğrenme süreçlerine taşımalarına neden olabilmektedir. Bunun yanı sıra, Türkçe yönelme hâli ekinin (+(y)A) düz-geniş ünlülü biçimlerine karşıllık, Eski Türkçedeki ünsüzle başlayan biçimlerin standartlaşmış halleri de, yine bu süreçte söz konusu özellikleriyle bir karışmaya yol açabilmekte; çıkma hali ekinin Türkçedeki düz-geniş ünlülü (+DAn) biçimlerine karşılık, ayrıca, lehçe konuşurlarının, ana dillerindeki standart biçimlerin etkisiyle, düz-dar ünlülü biçimleri tercih edebildikleri de görülmektedir. Ayrıca, belirtme hali 
ekinin, Türkçede $+(\mathrm{y}) \mathrm{X}$ biçiminde kullanımına karşılık, aynı eki ünsüzle başlayacak biçimde standartlaştıran Kazakça konuşurları, ana dillerindeki biçimin etkisiyle yine belirtme hali ekini 'biz+ni, kapı+nı' vb. örneklerde olduğu gibi kullanma eğiliminde olabilmektedirler. Türkçe ekfiilin (i-), Türk lehçelerindeki karşılığı olan er- biçimi yerine, ol- yardımcı fili ile karşılanması, Türk dilli halkların konuşurları tarafından Türkçe öğrenme sürecinde yapılan hataların tipik örneklerindendir. "O yıllarda ben öğrenci oldum.” örneğindeki gibi, ‘öğrenci idim/öğrenciydim’ biçimleri yerine 'öğrenci oldum' biçimini tercih eden öğrenicilerin bu türden hatalarında yine ana dillerindeki standart biçimlerin etkisi vardır (Durmuş 118-9).

Temel öğelerin dizilişi, niteleyen-nitelenen ilişkisi ve genel olarak hem bağımsız hem de bağımlı sözdizimsel unsurların görünümleri bakımından aynı veya benzer özelliklerle karakterize olan Türkçe ve Kazakça arasındaki sözdizimsel durumun yanı sıra, özelde öğrenici hatalarına dönüşen bazı farklılıklar da söz konusudur.

Bu bağlamda, Türk lehçelerinde filimsilerin kullanımına bakıldığında bunların çok düzenli işlediği söylenebilir. Fakat işlevleri açısından durumun bu kadar düzenli olduğu söylenemez. Örneğin Türkçede sıfatfillerin kullanımında ikili bir ayrışma görülür. 'Kitabı al-an ögrrenci’ veya 'öğrencinin al-diğg kitap’ kullanımları Türkiye Türkçesindeki - An ve -DXKsıfatfillerinin seçiminin hangi gramatikal şartlarda gerçekleştiğini gösterir. Diğer taraftan benzer bir sıfatfiil seçimi Kazakça gibi bazı lehçelerde görülmez. Türkiye Türkçesindeki - $A n$ ve - $D X K$ seçimi yerine -An sıfatfiil eki cümlenin unsurları arasında herhangi bir seçim yapmadan kullanılır (Erdem 72-3).

Aydın da, öğrenici hatalarına yönelik doküman inceleme yöntemiyle ortaya koyduğu veriler arasında söz dizimi düzeyinde 'tamlama', 'adlaştırma', 'cümle ögeleri arasında uyumsuzluk' ve 'bağlaçların kullanımı ile ilgi tespit edilen bir dizi yazılı anlatım ve dil bilgisi hatasından söz edilebileceğini belirtir. Tamlamalarla ilgili olarak, iyelik biçimlerinin kullanımı, belirsizlik sıfatlarıyla kurulan tamlamalarda çokluk ekinin kullanımı gibi hatalarının 
yanı sıra, cümle öğeleri arasında özne, yüklem, nesne ve tümleçlerin kullanımlarıyla ilgili yine pek çok hatanın tespit edildiğini kaydetmektedir (32-43).

Yılmaz, Kazakistan'da Türkçe öğrenen bir grup öğreniciyle gerçekleştirdiği anketle, öğrenicilerin Türkçe öğrenme sürecinde karşılaşmış oldukları güçlükleri belirlemeye çalışmıştır. Yılmaz’a göre, Kazak öğrenicilerin dinleme becerisi ile ilgili en önemli sorunlarından biri (ikinci sırada) sözcük hazinesinin zayıf olması (\%18.5) iken, aynı çalışmada öğrenicilerin sözcük bilgilerinin zayıf olduğuna dair görüşleri konuşma (\%30.6), okuma (\%24.9) ve yazma (\%23.1) becerilerinde ilk sırada yer almaktadır (265-72). Doğrudan Kazakça-Türkçe iki dilli sözlüklerin yanı sıra, Ahmet Yesevi Üniversitesinde olduğu gibi Türk Dünyasından öğrencilerin de yer aldığı Türkçe kurslarında, Türk dili ailesinin üyelerinin söz varlığını karşılaştırmalı olarak sunan Karşılaştırmalı Türk Lehçeleri Sözlüğü gibi nitelikli yayınlar da hem öğreniciler için çalışmalarında hem de öğreticiler için sözcük öğretimi materyalleri ve etkinlikleri hazırlama sürecinde yararlı olacaktır.

Türk dillilere Türkçe öğretimi alanını doğrudan etkileyen konulardan biri olarak, Türk dili ailesinin üyeleri arasındaki dilsel mesafeye (linguistic distance) dair bilimsel içerikli, uygulamalı çalışmalar bakımından fazla bilginin olduğunu söylemek güçtür. Bu konuda Türk dili ailesinin daha çok dil bilimsel, coğrafi yer adları, coğrafi yön adları ve etnik boy adları esasında nasıl tasnif edildiğine de bakılabilir. Ancak, Türk lehçeleri arasındaki mesafenin, Türk dillilere Türkçe öğretiminde çok önemli bir yeri vardır. Tarihsel ve modern Türkoloji alanlarındaki çalışmaların sağladığı veriler şüphesiz bu konuda çalışmak isteyeceklere önemli temel oluşturabilecek zenginliktedir. Bu verilerden yararlanarak hem Türk lehçelerinin doğal konuşurları hem de bu konuşurlar arasında Türkçeyi öğrenmeye başlayacaklarla ilgili; bu kişilerin kendi ülkelerinde veya Türkiye'de lehçe mesafe ölçüm araçları geliştirerek testler yapılmalıdır. Bu çalışmaların ortaya koyduğu veriler de, işlenerek, dil öğretimi alanında 
öğretmen yetiştirme, öğretim programı, ders araçları geliştirme süreçlerine taşınmalıdır (Durmuş 115-7).

\section{Kazak Öğrenicilerde Türk Kültürüne Yönelik Farkındalık Oluşturmak}

Öğrenicilerin dil öğrenme süreçlerinde dilsel mesafenin yanı sıra, psikolojik etkisinden bahsedilebilecek bir başka unsur, öğrenici dili ve kültürüyle hedef dil ve kültürü arasındaki mesafe konusunda fikir verebilecek bir diğer ölçüt olarak psikolojik mesafe (psychic distance) kabul edilebilir. Ilgaz-Sümer ve Üner'in (248-9) aktardığına göre, ilk olarak Beckerman'ın bir makalesinde (31-4) ele alınıp ticaretteki önemi sorgulanan, Uppsala Uluslararasılaşma Modeli'nde uluslararasılaşmanın açıklanmasında yararlanılan temel kavramlardan biri olarak psikolojik mesafe kavramı, ülkelerin göreceli mesafeleri olarak açıklanmaktadır ve alan yazında işletmelerin yabancı pazarlarda başarı elde edebilmeleri için öncelikle (ihracatın erken aşamalarında), psikolojik olarak kendi ülke pazarlarına yakın gördükleri ülkelere yönelmeleri gerektiği belirtilmektedir. Yine, Ilgaz-Sümer ve Üner’in (250) sunduğu bilgilere göre, Johanson vd. (308) psikolojik mesafenin iki ülke pazarı arasındaki kültür, dil, eğitim, endüstriyel gelişmişlik, politik sistem, din, saat dilimi, tarihsel bağlar başta olmak üzere çeşitli faktörlere bağlı olarak ortaya çıktığını belirtirken; özellikle Hofstede tarafından ortaya konulmuş olan ülkeler arası kültürel boyutlardaki farklılıklar da, ülkeler arası kültürel mesafenin nedenlerini açık bir biçimde göstermesi bakımından dikkat çekicidir. Araştırmacıların aktarmış oldukları yukarıdaki bilgilerin yanı sıra, ilgili kuramsal ve uygulamalı çalışmalardan da yararlanılarak yürüttükleri çalışmada (255) beş Türk Cumhuriyeti ile Türkiye arasındaki psikolojik mesafe ölçümünde, bu ülkelerin Türkiye'ye psikoloji mesafesi (endeksi) yakından uzağa şu şekilde sıralanmaktadır: ayrıca bu sıralamayla, Türkiye ve söz konusu ülkeler arasındaki ticaret ilişkileri önemli ölçüde paralellik göstermektedir: 1. Azerbaycan (2.02), 2. Kazakistan (2.36), 3. Özbekistan (2.69), 4. Kırgızistan (2.76) ve 5. Türkmenistan (3.09). Bu veriler, diğer bağımsız Orta Asya Türk Cumhuriyetleri arasında Kazakistan halkının Türkçe öğrenme sürecinde, coğrafi mesafe ve ona bağlı durumlar ile 
dilsel mesafenin daha kolay aşılabilmeyle ilgili psikolojik mesafe fırsatlarını ortaya koymaktadır. Bu psikolojik mesafe firsatları da öğrenicilerde hedef dil Türkiye Türkçesi ve ait olduğu kültürle ilgili farkındalık geliştirebilmeyle daha kolay gerçekleştirilebilecektir.

Kazakça ve Türkçe arasındaki yapısal durumun yanında, kültüre dair ortak tarihî ve güncel arka plan bilgisini oluşturan dönemler, olaylar, mekânlar, kişiler, objeler, ritüeller ve bunların dildeki görünümleri (en genel ifadeyle somut ve somut olmayan kültürel unsurlar), hem hedef dil konuşurlarının hem de öğrenicilerin kendi kültürel varlıklarıyla, yaşam ve düşünme biçimleriyle, değer yargılarıyla, sözel ve sözel olmayan davranış kalıplarıyla karşılaştırılarak ele alınabilir. Nitekim, Millı̂ Eğitim Bakanlığınca başlatılıp kuruluşunun ardından Yurtdışı Türkler ve Akraba Topluluklar Başkanlığına devredilen 'Büyük Öğrenci Projesi' kapsamında; eğitim, ulaşım, konaklama, sağlık, günlük yaşam ihtiyaçları karşılanarak 'Türk ve Akraba Topluluklar'dan Türkiye’ye getirilen öğrencilere ve mezun sayılarına bakıldığında, 2010 yılı sonu itibarıyla 3,093 Kazakistanlı öğrenciden sadece 1,023'ünün mezun olmasından hareketle, öğrencilerin önemli bir uyum sorunu yaşadıkları kaydedilmektedir. Benzer durum diğer ülkelerden gelen öğrenciler için de geçerlidir. Nitekim aynı şekilde Türkiye'ye getirilen 2,461 Kırgızistanlı öğrenciden 831'i mezun olabilirken, 1,915 Özbekistanlı öğrenciden 195'i, 3,779 Türkmenistanlı öğrenciden 1,662'si mezun olmuştur (Durmuş ve Yılmaz 546-7). Bu durum, tarihsel, kültürel, dilsel ortaklıklara ve yukarıda belirtilen psikolojik mesafe durumuna rağmen Türk Dünyasından öğrencilerin uyum sorunu yaşadıklarına dikkat çekmektedir. Bu uyum sorunun yarattığı/yaratabileceği olumsuzlukları gidermenin yollarından biri, şüphesiz, dil öğrenimleri sürecinde öğrencilerde hedef dile ve hedef dilin kültürüne yönelik farkındalık geliştirmek olacaktır. 


\section{Öğrenicinin Ana Dilinin Dil Öğretimindeki Yeri Sorunsalı}

Burada ele alınan ve temelde karşılaştırmalı açıklamalara veörneklendirmelere dayanan bir öğretim uygulaması, şüphesiz öğrenicilerin ana dili bakımından homojen, tek dilli sınıflarda mümkün olacaktır. Kimi zaman öğreticinin de öğrenicilerle aynı ana dili konuşuru olabildiği tek dilli sınıflarda, özellikle başlangıç düzeylerinde, öğretim veya sınıfın iletişim dili olarak öğrenici ana diline değişen oranlarda başvurulduğunu, bunu hem öğreticilerin hem de öğrenicilerin yararlı gördüğünü ortaya koyan çalışmalar bulunmaktadır.

Kuramcıların hedef dille sınırlı sınıf içi iletişim ısrarı karşısında, ana dilinin yabancı dil sınıflarında kullanılmadığı anlamına gelmezken (Cook, "Going" 201), dil öğreticilerinin kendilerini profesyonel istismardan dolayı suçlu hissetmelerine neden olabilecek kadar güçlü söz konusu yerleşik önyargılardan bahsedilebilir. Söz konusu önyargılar içerisinde, bunun yanı sıra, konuşulan dilin yazılandan daha temel olduğu, dilbilgisi konusundaki açık tartışmalardan kaçınılması ve dil öğretimi uygulamalarının ayrı bölümler hâlinde değil bir bütün olarak yürütülmesi gerektiği düşünceleri de yer alır (Cook, "Using" 402-423).

Öğrenicilerin ana dilinin öğretim sürecindeki yeriyle ilgili tartışmanın merkezinde, edinilen ana diliyle, hedefdilin vehattabunların dışındabilinenve öğrenilen öteki dillerin ilişkisinin bireyin zihninde nasıl işlemlendiği üzerine farklı görüşler yer almaktadır. Nitekim bireyin, dillerin yapısal ve anlamsal unsurlarını beyninde ayrı ayrı mı yoksa birlikte mi işlediği sorunsalıyla ilgili görüş farklılıklarının, dil öğretimine yaklaşımda belirleyici olduğunu ifade eden Cook’a ("Using" 402-423) göre, öğrenicinin ana dilini bütünüyle yok saymak, reddetmek, dilleri ayrı ayrı bölmelere koymaya çalışmak, bunlar birçok yönden birbirine bağlı oldukları için başarısızlığa mahkûmdur. Çünkü edinilen/öğrenilen dil, sadece arkada bir uzantı inşa ederek eve oda eklemekle kalmaz, tüm iç duvarları yeniden inşa eder. Bu bağlamda, ana dilinin (veya daha önce edinilmiş diğer dillerin) sınıftan dışlanmasını, hedef dilin, öğretimin hem nesnesi hem de tek aracı olmasını sağlamaya odaklı 
tek dilli ilke (monolingual principle) karşısında anlamı karşılamak için yararlanılan iki dilli (bilingual) teknikler en eski dil öğretim teknikleri olarak kabul edilir (Butzkamm 471). Bu görüşleri destekleyici şekilde, dil öğrenicilerinin bazen ana dilinin etkisinin bir sonucu olarak yanlışlar yapmasına rağmen, öğrenicilerin doğru yaptıkları birçok şeyin buna atıfta bulunarak yapıldığını savunan Swan'e (85'ten alıntılayan Holthouse 27) göre "Aslında, yabancı dile ait unsurlarla ana diline ait olanlar arasında karşılaştırmaya dayalı uygunluklar geliştirilmeye devam edilmezse, asla yabancı dil tam olarak öğrenilmez." (Holthouse 27). Bütün bunların ardından, özellikle sınıf içi uygulamaların gerçekleştirilebilmesinde örneğin ikili ve grup çalışması oluşturmada, amaca uygun ve açık bir biçimde çalışmayan bir etkinliği düzenlemekte, anlamanın gerçekleşip gerçekleşmediğini kontrol etmede, bununla da ilişkili olarak, öğretimin ve tabii öğrenimin hızının planlanan biçimde devamlılı̆̆ını sağlamada yönetsel işlevler taşıdığı için öğrenicilerin ana diline sınırlı olarak yer vermenin yararlı olacağı düşünülmektedir (Atkinson).

Bunun nasıl uygulanacağı konusunda da, Littlewood ve Yu (70-4) öğrenicilerin hedef dille ilgili anlama, içselleştirme ve üretimlerine yardımcı olmak için tasarlanmış, stratejik olarak kullanılabilecek belirli teknikler ve görevler çerçevesi sunar. Buna göre; ana dili planlı bir yardım aracı olarak stratejik kullanılabilir. Çünkü hedef dile dair sözcüklerin, yapıların ve ifadelerin anlamlarını belirginleştirmede ana dili etkili bir araç olabilir; böylelikle de etkin kullanım ve içselleştirmenin önemli aşamalarına daha hızlı geçiş yapabilir. Bu amaçla, Dodson ve Butzkamm (32-33) tarafından, diyalogların sunumunda, hedef dilde ifade edilen sözcüklerin, yapıların, anlamların; öğrenicilerin bilişsel sistemine yerleştirilip daha sonra hedef dil üzerinden yeniden ifade edildiği (hedef dil $\rightarrow$ ana dili $\rightarrow$ hedef dil dizisinde) 'sandviç tekniği' adıyla bir teknik önerilmiştir. Yapıların sunumunda, hedef dil ve ana dili arasındaki karşılaştırma, yeni ve tanıdık arasında bağlantılar oluşturarak (Aynı zamanda öğrencilerin genel dil bilincini 
daha da artırabilir.) güven duygusunu artırmaya da yardımcı olabilir. Uygulama aşamasında, "iki dilli yöntemin” kilit bileşeni, eşdeğer hedef yapıları ortaya çıkarmak için ana dilindeki uyaranların tekrarla kendisini gösteren bir sondaj aracı gibi kullanılmasıdır. Burada önemli bir nokta, eşdeğerliğin kelime düzeyinde değil, anlam düzeyinde olmasıdır: anlamlar öğrenicinin bilişsel sistemine yerleştirilir ve sonra hedef dil aracilığıyla yeniden ifade edilir. Bu, öğrenicilerin, onlardan kaçınmak için iletişim stratejilerini kullanabileceklerinden, nadiren karmaşı yapıları kullanmaya zorlandığı tek dilli iletişimsel faaliyetlerin zayıflığını telafi edebilir. Hatta öğreticiler, hedef dilde üretimin önceki aşamasında, öğrenicilerin ana dili kullanım durumlarından başlayan (yani hedef dilde sunmak üzere ana dilinde hazırlık yapma veya doğrudan ana dilinde hazırlık yapıp bunları hedef dilde yeniden ifade etme gibi) ve hedef dilde girdi oluşturmaya yönelik teşvik edici işlev gören etkinlikler tasarlayabilir.

\section{Sözel/Sözel Olmayan İletişim Tercihleri Bakımından (Pragmatik Açıdan) Dil Öğretimi ve Türkçe ile Kazakçanın İstek (Rica) Söz Edimi Tercihleri Bakımından Karşılaştırılması}

Paradowski, dil pedagojisinde karşılaştırmalı bir yaklaşımı uygulamanın gerekçelerini ortaya koyarken, bu gerekçenin, öğrenici hatalarını analiz edilebilmeye imkân sunmasının yanı sıra, kültürlerarası yetkinliği teşvik eden Diller İ̧̧in Avrupa Ortak Başvuru Metninde de vurgulandığı gibi, sadece belirli durumlarda kullanım için hangi dilin/yapının uygun olduğunu bilmekle (sosyo-dilbilimsel yeterlilik) değil, aynı zamanda bu uygunluğun kültürler arasında nasıl farklılaştığını bilmekle de ilgili olduğunu belirtmektedir. Ayrıca, hedef dille ve kültürüyle ilgili bu karşılaştırmalı uygulamanın, sadece hedef dil için değil öğrenicinin ana dili ve kültürü için de belirli bir farkındalı̆̆g geliştirdiği, yani iki yönlü süreç olarak değerlendirilebileceğini belirten Paradowski, hedef dildeki yetkinliğin önemli bir parçasının "pragmatik akıcılık" olduğunu belirtmekte; hedef dile dair farkındalık kavramının, dil sisteminin boyutlarının ötesinde dilin 
iletişimsel olarak kullanılmasına kadar genişletildiğini savunan House'un görüşünü hatırlatmaktadır (10-11).

Hedef dilin konuşurlarının bu sözel veya sözel olmayan davranışlarını ve bunların ardındaki düşünme biçimlerini, öğrenicilerin ana dilindeki biçimleriyle karşılaştırarak sunmak, yukarıda belirtildiği gibi, hedef dilde geniş anlamdaki dilsel-kültürel yetkinlik için önemli ve gereklidir.

İlgili alanyazına bakıldığında, Wolfson (1981) dillerin etkileşim desenleri ve normları açısından birbirlerinden büyük ölçüde farklılaştığını belirtmektedir. Bu farkların tespiti, tipolojik, kültürel, işlevsel ayrımların farkına varılıp uygun yaklaşım ve yöntemlerin geliştirilmesi açısından önemlidir. Alanyazında bu amaçla gerçekleştirilmiş birçok kültürlerarası ve edimbilimsel çalışma bulunmaktadır. Bu çalışmalarda öneride bulunma, iltifat, reddetme, özür dileme, rica etme gibi birçok dilsel işlev ve söz edimi kullanımı karşılaştırılmıştır. İltifat kullanımlarına ilişkin Wolfson, Chen, Nelson et al.; selamlaşma kullanımlarının incelendiği Ebsworth et al.; öneride bulunma söz edimi için Koike ve Alaoui gibi araştırmacıların çalışmaları örnek olarak gösterilebilir. İstek (rica) söz ediminin incelendiği araştırmalar da bu alanda birçok dil arasında gerçekleştirilmiş çalışmalar arasındadır. Blum-Kulka ve Olshtain’ın İngilizce (Avustralyalı, Amerikan ve İngiliz katılımcılarla), Kanada Fransızcası, Danca, Almanca, İbranice ve Rusça ana dili konuşurları arasında uygulanıp istek (rica) söz edimlerinin karşılaştırmalı olarak incelendiği çalışması birçok sonraki araştırmanın da başvuru kaynağı olmuştur. Adı geçen çalışmada, katılımcıların istek (rica) kullanımlarında ne gibi stratejiler izlediği, hangi söz kalıplarını kullandıkları ve diller/ kültürler arasındaki benzerlikler/farklar ortaya konulmuştur. İstek, rica ve incelik konularının incelendiği diğer çalışmalara ise Brown ve Levinson, Geis ve Harlow, Ogiermann, Yang, Jalilifar, Han, Abuarrah et al., Koneva, Ebadi ve Seidi, Kotorova, Yazdanfar ve Bonyadi tarafından yürütülmüş çalışmalar örnek olarak gösterilebilir. Bu çalışmalarda Almanca, Arapça, 
Rusça, Lehçe, İngilizce, Çince, Farsça gibi birçok dil karşılaştırılmış, dilsel ve kültürel benzerlikler/farklılıklar tespit edilmeye çalışılmıştır.

Türkçe ve yabancı dil olarak Türkçe öğretimi ile ilgili de benzer çalışmalar yapılmıştır. Bunlara örnek olarak Dogancay-Aktuna ve Kamish, Marti, Polat (Yabancı Dil, "Fransızca"), Gökmen ve Çağlayan Dilber, Tabar, Asmalı ve Yavuz ve Özdemir gösterilebilir. Bir başka çalışmada, Kılınç Türkçenin ana dili konuşurları ile B1 düzeyinde yabancı dil olarak Türkçe yeterliliğine sahip Kazak öğreniciler arasında Türkçe istek (rica) söz edimi stratejilerini incelemiştir. Çalışmaya Türk Hava Kurumu Üniversitesi hazırlık sınıfında öğrenimlerine devam eden 42 Türk öğrenci ve 2'si Gazi Üniversitesi TÖMER'de, 18'i Kazakistan Ahmet Yesevi Üniversitesinde bulunan B1 düzeyindeki yabancı dil olarak Türkçe öğrenen toplam 20 Kazak öğrenci katılmıştır. Katılımcılara "birinden bir şey istemeleri" gereken ve 12 durumdan oluşan bir Konuşma Tamamlama Testi verilmiş ve verilen yanıtlar Blum-Kulka ve Olshtain'ın önerdiği strateji ve alt strateji türlerine göre sınıflandırılmıştır. Blum-Kulka ve Olshtain 3 ana istek stratejisi tanımlamaktadır: Doğrudan istek stratejisi, standartlaşmış dolaylı istek stratejisi ve standartlaşmamış dolaylı istek stratejisi. Doğrudan strateji, isteğin açık bir biçimde doğrudan gerçekleştirildiği "emir" ifadeleri gibi kullanımlarıdır. Standartlaşmış dolaylı istek stratejisi dillere yerleşmiş ve yaygın olarak kullanılan incelik kullanımları iken, standartlaşmamış dolaylı istek stratejileri de dolaylı bir şekilde ifade edilen fakat yaygın ve kalıplaşmış kullanımlar yerine "ipucu” gibi stratejilerdir.

Blum-Kulka ve Olshtain, bu stratejilere ek olarak 9 alt strateji belirlemiştir (Blum-Kulka ve Olshtain'dan aktaran Kılınç). 


\section{Tablo 1}

Strateji Türü ve Örnekleri

\begin{tabular}{ll}
\hline Strateji türü & Örnek \\
1- Emir İfadeleri & Beni yalnız bırak! \\
(Mood Derivable) & Burayı temizle lütfen! \\
2- Açı Edimseller & Sizden aracınızı buraya park etmemenizi \\
(Explicit Performative) & istiyorum. \\
3- Sınırlı Edimseller & Sizden dersi bir hafta erken vermenizi \\
(Hedged Performative) & rica ediyorum. \\
4- Zorunluluk Bildiren İfadeler & Aracınızı çekmek zorundasınız! \\
(Obligation Statements) & \\
5- İstek Bildiren İfadeler & Beni rahatsız etmeyeceğinizi umuyorum. \\
(Want Statements) & \\
6- Öneri Bildiren İfadeler & \\
(Language Specific Suggestory & Temizlik yapmaya ne dersin? \\
Formula) & \\
7- Hazırlayıcı Koşullara & \\
Gönderme (Reference to & Lütfen mutfağı temizler misin? \\
Preparatory Conditions) & \\
8- Güçlü İpucu & \\
(Strong Hints) & Mutfağı çok kirli bırakmışsın! \\
9- Hafif İpucu (Mild Hints) & Ben bir rahibeyim (ısrarcı çocuğa ceva- \\
\hline
\end{tabular}

Bu tabloda ilk 5 strateji doğrudan isteklerin, 6. ve 7. stratejiler standartlaşmış dolaylı isteklerin ve son iki strateji standartlaşmamış dolaylı isteklerin alt stratejileridir. Katılımcilara verilen Konuşma Tamamlama Testi ve testte bulunan 12 farklı duruma verdikleri yantların Blum-Kulka ve Olshtain tarafından oluşturulan yukarıdaki strateji türlerine göre incelemesi yapılırken her bir strateji ve alt strateji için sayısal değerler kullanılmış ve veriler SPSS programı aracıllğıyla değerlendirilmiştir. Bu çalışmada hem gruplardaki katılımcı sayılarını eşitlemek hem de daha önceki çalışmanın sayıca eşit örneklemlerde yinelenebilirliğini/güvenirliğini test etmek amacıyla rastgele seçilen 20 Türk katılımcı kullanılmıştır. Sonuçların önceki çalışmayla paralellik gösterdiği görülmüştür. Bunun yanı sıra, katılımclların istek (rica) 
söz edimi stratejileri ile alt stratejileri sıklıklarına ve kullanıldıkları bağlamlara göre incelenmiş olup tablolaştırılmış ve yorumlanmıştır. Aşağıdaki tabloda Türk ve Kazak katılımcıların her bir durum için yanıtları görülmektedir:

Tablo 2

Türk ve Kazak Katılımcıların İstek (Rica) Söz Edimi Kullanım Stratejileri

\begin{tabular}{ccccccc}
\hline Uyruk & Türk & \multicolumn{5}{c}{ Kazak } \\
\hline Strateji & $\begin{array}{l}\text { Doğru- } \\
\text { dan }\end{array}$ & $\begin{array}{l}\text { Standart- } \\
\text { laşmış } \\
\text { Dolaylı }\end{array}$ & $\begin{array}{l}\text { Standart- } \\
\text { laşmamış } \\
\text { dolaylı }\end{array}$ & $\begin{array}{l}\text { Doğru- } \\
\text { dan }\end{array}$ & $\begin{array}{l}\text { Standartlaş- } \\
\text { mış Dolaylı }\end{array}$ & $\begin{array}{l}\text { Standart- } \\
\text { laşmamış } \\
\text { dolaylı }\end{array}$ \\
\hline D1 & 10 & 9 & 1 & 7 & 11 & 2 \\
D2 & 2 & 17 & 1 & 8 & 11 & 0 \\
D3 & 2 & 17 & 1 & 5 & 13 & 2 \\
D4 & 6 & 13 & 1 & 11 & 3 & 3 \\
D5 & 0 & 20 & 0 & 0 & 20 & 0 \\
D6 & 1 & 17 & 2 & 1 & 18 & 1 \\
D7 & 9 & 10 & 1 & 6 & 12 & 0 \\
D8 & 0 & 15 & 4 & 0 & 18 & 1 \\
D9 & 6 & 13 & 0 & 3 & 14 & 1 \\
D10 & 2 & 17 & 1 & 4 & 14 & 1 \\
D11 & 11 & 3 & 5 & 11 & 4 & 3 \\
D12 & 1 & 7 & 12 & 0 & 11 & 7 \\
\hline Toplam & $\mathbf{5 0}$ & $\mathbf{1 5 8}$ & $\mathbf{2 9}$ & $\mathbf{5 6}$ & $\mathbf{1 4 9}$ & $\mathbf{2 1}$ \\
\hline
\end{tabular}

$\mathrm{Bu}$ tabloya göre, Türklerin ve Kazakların birbirine benzer stratejiler kullandıkları öne sürülebilir. Türkler toplamda 158, Kazaklar da 149 kez tercih ederek en fazla "standartlaşmış dolaylı" stratejiyi kullanmıştır. Bunun akabinde, Türkler 50 kez, Kazaklar 56 kez doğrudan stratejiye başvurmuştur. Türkler 29 kez "standartlaşmamış dolaylı" stratejisini kullanırken, Kazaklar bu stratejiyi kullanarak $21 \mathrm{kez}$ istekte bulunmuştur.

Sayısal olarak doğrudan kullanımların 1, standartlaşmış dolaylı kullanımların 2, standartlaşmamış dolaylı kullanımların 3 olarak girildiği 
verilerin ortalamaları alındığında, Türklerin ortalama kullanımları 1,91 iken, Kazakların 1,84’tür. Küçük farklarla da olsa, Türklerin Kazaklara göre daha "dolaylı" bir şekilde istekte bulunduğu görülmektedir.

Katılımcıların kullandıkları alt stratejilere bakıldığında ise, aşağıdaki tablolarda belirtilen veriler elde edilmiştir:

\section{Tablo 3}

Türk Katılımcıların Kullandıkları Alt Stratejiler

\begin{tabular}{|c|c|c|c|c|c|c|c|c|c|}
\hline \multicolumn{10}{|c|}{ Ana Dili Olarak Türkçe Konuşurları } \\
\hline $\begin{array}{l}\text { Alt } \\
\text { Stra- } \\
\text { teji } \\
\text { Türü }\end{array}$ & $\begin{array}{l}\text { Emir } \\
\text { Ífa- } \\
\text { desi }\end{array}$ & $\begin{array}{l}\text { Açık } \\
\text { edim- } \\
\text { sel }\end{array}$ & $\begin{array}{l}\text { Sinırlı } \\
\text { Edim- } \\
\text { sel }\end{array}$ & $\begin{array}{l}\text { Zo- } \\
\text { runlu- } \\
\text { luk } \\
\text { Bildi- } \\
\text { ren }\end{array}$ & $\begin{array}{l}\text { İstek } \\
\text { İfa- } \\
\text { deleri }\end{array}$ & $\begin{array}{l}\text { Hazır- } \\
\text { layıcı } \\
\text { koşulla- } \\
\text { ra gön- } \\
\text { derme }\end{array}$ & Öneri & $\begin{array}{l}\text { Güç- } \\
\text { lü } \\
\text { ipucu }\end{array}$ & $\begin{array}{l}\text { Hafif } \\
\text { ip- } \\
\text { ucu }\end{array}$ \\
\hline D1 & 7 & - & - & - & - & 5 & 7 & 1 & - \\
\hline D2 & - & - & - & - & - & 17 & 2 & 1 & - \\
\hline D3 & 1 & - & - & - & 1 & 17 & - & 1 & - \\
\hline D4 & 6 & - & - & - & - & 13 & - & 1 & - \\
\hline D5 & - & - & - & - & - & 20 & - & - & - \\
\hline D6 & 1 & - & - & - & - & 17 & - & 2 & - \\
\hline D7 & 9 & - & - & - & - & 9 & 1 & 1 & - \\
\hline D8 & - & - & - & - & - & 14 & 1 & 4 & - \\
\hline D9 & 6 & - & - & - & - & 10 & 3 & - & - \\
\hline D10 & - & - & - & - & 2 & 17 & - & 1 & - \\
\hline D11 & 9 & - & - & 1 & 1 & 1 & 2 & 4 & 1 \\
\hline D12 & - & - & - & 1 & 1 & 1 & 6 & - & 1 \\
\hline $\begin{array}{l}\text { Top- } \\
\text { lam }\end{array}$ & 39 & 0 & 0 & 2 & 5 & 141 & 22 & 16 & 2 \\
\hline
\end{tabular}

Buna göre, Türk katılımcılar 141 kez "hazırlayıcı koşullara gönderme" altstratejisini kullanmıştır. Bunun ardından en fazla kullanılan stratejinin "emir ifadeleri” (39 kez) olduğu görülmektedir. Emir ifadelerini takiben, 22 kez "öneri” ve 16 defa "güçlü ipucu stratejisi tercih edilmiştir. 
Tablo 4

Kazak Katılımcıların Kullandıkları Alt Stratejiler

\begin{tabular}{|c|c|c|c|c|c|c|c|c|c|}
\hline \multicolumn{10}{|c|}{ Yabancı Dil Olarak Türkçe Öğrenen B1 Düzeyindeki Kazak Öğreniciler } \\
\hline $\begin{array}{l}\text { Alt } \\
\text { Strateji } \\
\text { Türü }\end{array}$ & $\begin{array}{l}\text { Emir } \\
\text { İfa } \\
\text { desi }\end{array}$ & $\begin{array}{l}\text { Açık } \\
\text { edim- } \\
\text { sel }\end{array}$ & $\begin{array}{l}\text { Sinırlı } \\
\text { Edim } \\
\text { sel }\end{array}$ & $\begin{array}{l}\text { Zorun- } \\
\text { luluk } \\
\text { Bildi- } \\
\text { ren } \\
\end{array}$ & $\begin{array}{l}\text { İstek } \\
\text { İfa } \\
\text { desi }\end{array}$ & $\begin{array}{l}\text { Hazırlayıcı } \\
\text { koşullara } \\
\text { gönderme }\end{array}$ & $\begin{array}{l}\text { Öne- } \\
\text { ri }\end{array}$ & $\begin{array}{l}\text { Güçlü } \\
\text { ipucu }\end{array}$ & $\begin{array}{l}\text { Hafif } \\
\text { ipucu }\end{array}$ \\
\hline D1 & 4 & - & - & - & 3 & 7 & 4 & 2 & - \\
\hline D2 & 1 & 1 & - & - & 6 & 11 & - & - & - \\
\hline D3 & - & - & - & - & 5 & 11 & 2 & 2 & - \\
\hline D4 & 5 & - & - & - & 6 & 3 & - & 3 & - \\
\hline D5 & - & - & - & - & - & 20 & - & - & - \\
\hline D6 & - & - & - & - & 1 & 18 & - & 1 & - \\
\hline D7 & 5 & & & 1 & - & 11 & 1 & - & - \\
\hline D8 & - & - & - & - & - & 17 & 1 & - & 1 \\
\hline D9 & 3 & - & - & - & - & 9 & 5 & 1 & - \\
\hline D10 & - & - & - & - & 4 & 14 & - & 1 & - \\
\hline D11 & 8 & - & - & 2 & 1 & - & 4 & 3 & - \\
\hline D12 & - & - & - & - & - & - & 11 & 6 & 1 \\
\hline Toplam & 26 & 1 & & 3 & 26 & 121 & 28 & 19 & 2 \\
\hline
\end{tabular}

Kazak katılımcıların da Türkler gibi en fazla "hazırlayıcı koşullara gönderme" stratejisini kullandıkları görülmektedir. Bunun ardından 28 ile “öneri”, 26’şar kez "emir" ve "istek" ve 19 defa "güçlü ipucu” alt stratejileri kullanılmıştır.

Aşağıdaki tabloda en sık kullanılan alt stratejiler, büyükten küçüğe sıralanmıştır:

Tablo 5

Türk ve Kazak Katılımcıların Sırayla En Fazla Kullandıkları Alt Stratejiler

\begin{tabular}{lll}
\hline $\begin{array}{l}\text { Kullanılan Alt } \\
\text { Strateji }\end{array}$ & Türk Katılımcılar & Kazak Katılımcılar \\
\hline $\mathbf{1}$ & Hazırlayıcı koşullara gönderme & Hazırlayıcı koşullara gönderme \\
& $-\quad 141$ & -121 \\
$\mathbf{2}$ & Emir İfadeleri -39 & Öneri -28 \\
$\mathbf{3}$ & Öneri -22 & Emir -26 \\
& & İstek -26 \\
$\mathbf{4}$ & Güçlü ipucu -16 & Güçlü ipucu -19 \\
\hline
\end{tabular}


Görüldüğü gibi, ana dili konuşurları Türkler yabancı dil olarak Türkçe öğrenen Kazaklara oranla daha fazla "hazırlayıcı koşullara gönderme" stratejisini kullanmıştır. En fazla kullanılan ikinci alt stratejide ise iki grup arasında farklılık görülmektedir. Türkler "emir ifadelerine" daha fazla başvururken, Kazaklar "öneri bildiren” alt stratejiyi kullanmıştır. Türklerin en fazla kullandığı 3. alt strateji "öneri bildiren” strateji iken, Kazakların bu sıralamada "emir ve istek ifadelerini”" eşit şekilde kullandıkları görülmüştür. Hem Türklerin, hem Kazakların en fazla kullandıkları 4. alt strateji "güçlü ipucu" olmuştur.

Bu verilerde ilk dikkati çeken, Türklerin 39 kez "emir ifadesi" kullanmasına karşın, Kazaklarda bu sayının 26'da kalmasıdır. Türkler, Kazak katılımcılara göre daha az doğrudan kullanımda bulunmasına rağmen, doğrudan ifadelerinin büyük çoğunluğunu "emir ifadeleri" oluşturmuştur. Bunun yanı sıra, Türk katılımcıların sadece 5 kez "istek ifadesi” kullandığı görülürken, Kazak katılımcılar 26 kez bu alt stratejiyi kullanmıştır. İstek ve emir ifadeleri de, Kazakların doğrudan kullanımlarının çoğunluğunu oluşturmaktadır. $\mathrm{Bu}$ ifadelerin 2, 3 ve 4. durumlarda en fazla kullanıldığı (toplam 17) görülmektedir. Bu durumlarda sırasıyla "yetkiliden, öğretmenden ve garsondan bir şey isteme" bağlamları verilmiştir. Türkler 2. ve 3. durumlarda sadece 2 kez doğrudan istekte bulunmuş; 4. durum olan "garsondan bir şey isteme" bağlamında 6 kez "emir ifadesine" başvurmuştur. Böylece, bahsi geçen durumlarda Türkler sadece 8 kez "doğrudan” bir istekte bulunurken, Kazaklarda bu sayı 24’tür.

Buna ek olarak, katılımcıların "ev arkadaşından mutfağı temizlemesini" istediği 1. durumda ana dili konuşuru Türkler emir ve öneri stratejisini toplamda 14 kez kullanırken, Kazaklar emir ve öneri stratejisini toplam 8 kez kullanmıştır. "Hiç tanımadıkları birinden/birilerinden" istekte bulunmaları gereken 5. ve 6. durumlarda hem Türkler hem Kazaklar standartlaşmış dolaylı istek alt stratejisi olan "hazırlayıcı koşullara gönderme" seçeneğine başvurmuştur. 7. durumda da tanımadıkları biri söz konusudur ancak bu kez "kütüphanede gürültü yapan kişilerden sessiz olması" istenmektedir. Böyle 
bir durumda Türkler Kazaklara göre daha fazla doğrudan istekte bulunmuş ve 9 defa "emir" cümlesi kurmuştur. 8. durum olan "market yetkilisinden istekte/ricada" bulunmayla ilgili bağlamda hemen hemen benzer bir sonuç görülmektedir. 9. durumda "ev arkadaşının elektrikli süpürgeyi açması sonucu uyanan kişinin arkadaşından bu işi daha sonra yapmasıyla ilgili istekte bulunması" istenmiş ve Türk katılımcılar daha fazla "emir ifadesi”" kullanmıştır. 10 ve 11. durumlarda sırasıyla "iş ilanı için yetkiliden bilgi isteme" ve "ders notu talep eden sınıf arkadaşının bu duruma son vermesini isteme" bağlamları verilmiştir. Bu iki durumda da sonuçlar benzerdir. Sonuncu durumda Kazakların Türklere göre daha fazla "öneri" ve "güçlü ipucu” alt stratejilerini kullandıkları görülürken, Türk öğrencilerin bir kısmının son soruya yanıt vermemiş olduğu da değerlendirmeye katılmalıdır.

Genel olarak, çalışmada en çok "standartlaşmış dolaylı istek stratejisi" kullanılırken, Türkler bu stratejiyi Kazaklara oranla biraz daha fazla kullanmıştır. İkinci en sık kullanılan strateji "doğrudan istek stratejisi” ve sonuncusu "standartlaşmamış dolaylı istek stratejisi” olmuştur. Alt stratejilerde, Türkler en çok "hazırlayıcı koşullara gönderme” ve ardından "emir ifadeleri" stratejilerine başvurmuşken, Kazaklar "hazırlayıcı koşullara gönderme” ve “öneride bulunma” stratejilerini kullanmıştır. "Emir ifadeleri” kullanımında Türkler Kazaklara göre daha yüksek bir orana sahipken, "istek ifadelerinde" Kazaklar ve Türkler arasında Kazak katılımcıların kullanımları lehine ciddi bir fark ortaya çıkmıştır.

Kazaklar "bir yetkili, öğretmen ve garsondan" istekte bulundukları üç durumda "sizden şunu istiyorum" ve "ben şunu yapmak istiyorum" şeklinde cümleler kurarken, Türklerde bu kullanım örnekleri neredeyse hiç görülmemiştir. Hatta yetkili birinden (müdür) bir şey istemeleri gereken 2. durumda hiç doğrudan kullanımları bulunmazken, öğretmenden bir şey istedikleri 3. durumda sadece 1 emir ve 1 istek ifadesi olmak üzere toplam 2 adet doğrudan yanıt görülmüştür. Tüm bunların yanı sıra, çalışmanın sınırlılıkları düşünüldüğünde sayıca daha büyük bir katılımcı grubuyla yinelenmesi önerilmektedir. 


\section{Sonuç}

Karşılaştırmalı ögretim yaklaşımı, lehçeler arası öğretim için yararlanılabilecek bir yaklaşım olarak kabul edilebilir. Bu yaklaşımda, hedef dile dair izole edilmiş yepyeni dilsel veya dil dışı yapılar inşaa etmek yerine öğrenicilerin mevcut bilgilerinden yola çıkmak; öğrenmeyi kolaylaştırabilir, hata analizinde yararlı olabilir ve hedef dile ve o dilin de içerisinde yer aldığ kültüre dair daha fazla farkındalık geliştirebilir. Öğrenicilerin ana diline, hedef dili öğrenme sürecinde engelleyici bir unsur olarak değil, stratejik kullanılabildiğinde hedef dilin en önemli destekçisi olarak yaklaşmak gerekir. Farklı veya ortak dilsel yapılar, yine ortak veya farklılaşan kültürel unsurlar, öğrenicilerin arka plan bilgilerinden yararlanma firsatı sunduğundan, öğrenicilerin dinledikleri veya okudukları dilsel girdileri, bu nitelikte olmayan içeriklere göre daha iyi anlamalarını sağlayacağı öngörülmektedir; ancak bunun, uygulamaya dalı çalışmalarla test edilmesi gerekir.

Ana dili Türkçe olan üniversite hazırlık sınıfı öğrencileri ile B1 düzeyindeki yabancı dil olarak Türkçe öğrenen Kazak öğrenciler arasında Türkçe istek (rica) kullanımı ve çeşitli bağlamlarda gösterilen doğrudanlık açısından bazı benzerlikler ve farklar görülmüştür. Bu benzerliklerin ve farklılıkların, öğretim süreçlerine uygun bir biçimde taşınabilmesi durumunda olumlu katkı yapacağı; öğreticilerin üst dilsel (metalinguistik) ve kültürlerarası farkındalık düzeylerini artıracağı değerlendirilmektedir.

\section{Kaynaklar}

Abuarrah, S. Sufyan et al. "Cross Cultural Pragmatics Requests' Use of Strategy and Level of Directness in Palestinian Arabic and British English.” AnNajah University Journal for Research (Humanities), no. 27, 2013, pp. 1109-1144.

Alaoui, Sakina M. "Politeness Principle: A Comparative Study of English and Moroccan Arabic Requests, Offers and Thanks.” European Journal of Social Sciences, vol. 20, no. 1, 2011, pp. 7-15.

Asmall, Mehmet, ve Aysun Yavuz. "The Apology Strategies of Turkish, Polish and Latvian Prospective English Teachers." International Journal of Language Studies, vol. 8, no. 3, 2014, ss. 55-84. 
Atkinson, David. "The Mother-tongue in the Classroom: A Neglected Resource?." ELT Journal, vol. 41, no. 4, 1987, pp. 241-247.

Aydın, Özgür. "Azeri, Kazak, Özbek ve Türkmen Öğrencilerde Türkçe Öğrenim Sorunları II: Sözdizimine İlişkin Yanlışlar.” Dil Dergisi, no. 20, 1994, ss. $32-43$.

Blum-Kulka, Shoshana, and Elite Olshtain. "Requests and Apologies: A CrossCultural Study of Speech Act Realization Patterns (CCSARP).” Applied Linguistics, vol. 5, no. 3, 1984, pp. 196-213.

Brown, Penelope, and Stephen C. Levinson. Politeness: Some Universals in Language Usage 4. Cambridge University Press, 1987.

Butzkamm, Wolfgang. "We Only Learn Language Once: The Role of The Mother Tongue in FL Classrooms: Death of a Dogma." Language Learning Journal, vol. 28, no. 1, 2003, pp. 29-39.

Butzkamm, Wolfgang. "Monolingual Principle." Routledge Encyclopedia of Language Teaching and Learning, ed. M. Byram ve A. Hu, Routledge Taylor \& Francis Group, 2017, pp. 471-474.

Chen, Rong. "Responding to Compliments A Contrastive Study of Politeness Strategies Between American English and Chinese Speakers." Journal of pragmatics, vol. 20, no. 1, 1993, pp. 49-75.

Cook, Vivian. "Going Beyond the Native Speaker in Language Teaching Author." TESOL Quarterly, vol. 33, no. 2, 1999, pp. 185-209.

Cook, Vivian. "Using the First Language in The Classroom." The Canadian Modern Language Review, vol. 57, no. 3, 2001, pp. 402-423.

Dodson, Charles J. Language Teaching and the Bilingual Method. Pitman, 1972.

Dogancay-Aktuna, Seran, ve Sibel Kamish. "Linguistics of Power and Politeness in Turkish." Linguistic Politeness Across Boundaries: The case of Greek and Turkish. John Benjamins Publishing Company, Amsterdam, 2001, ss. 75104.

Durmuş, Mustafa. Yabancılara Türkçe Öğretimi. Grafiker Yayınları, 2013.

Durmuş, Mustafa, ve Harun Yılmaz. “Son Yirmi Yılda Türkiye’nin Orta Asya’ya Yönelik Dış Politikası ve Bölgedeki Faaliyetleri.” Bă̆ımsızlıklarının Yirminci Yılında Orta Asya Cumburiyetleri Türk Dilli Halklar - Türkiye ile İlişkiler, Atatürk Kültür Merkezi Yayınları, 2012, ss. 485-586.

Ebadi, Saman, and Narges Seidi. "Iranian EFL Learners Request Strategies 
Preferences across Proficiency Levels and Gender." Journal of Applied Linguistics and Language Research, vol. 2, no. 4, 2015, pp. 65-73.

Ebsworth, Miriam et al. "Cross-cultural Realization of Greetings in American English.” Speech Acts Across Cultures: Challenges to Communication in a Second Language, Mouton de Gruyter, 1995, pp. 89-108.

Ercilasun, Ahmet Bican. "Türk Lehçelerinin Anlaşılmasında Dikkat Edilecek Noktalar.” Türk Dünyası Üzerine Makaleler-İncelemeler, Akçağ Yayınları, 1993, ss. 76-99.

Erdem, Mevlüt. “Türk Dili Tipolojisi Üzerine”. Alkış Bitiği Kemal Eraslan Armă̆anı, TKAE Yayınları, 2015, ss. 67-76.

Geis, Michael, and Linda L. Harlow. "Politeness Strategies in French and English." Speech Acts Across Cultures, 1996, pp. 129-135.

Gökmen, Seda, ve Nilay Çağlayan Dilber. "Türkçe Derslerinde Söz Edimlerin Öğretimi Üzerine Bir Değerlendirme.” Dil Dergisi, no. 154, 2011, ss. 4460.

Han, Xiuping. "A Contrastive Study of Chinese and British English Request Strategies Based on Open Roleplay." Journal of Language Teaching \& Research, vol. 4, no. 5, 2013, pp. 1098-1105.

Holthouse, John. "The Role of The Mother Tongue in EFL Classrooms." Gaikokugokyoiku Forum, no. 5, 2006, pp. 27-37.

Ilgaz-Sümer, Selay, ve M. Mithat Üner. "Türkiye ile Orta Asya Türk Cumhuriyetleri Arasındaki Psikolojik Mesafe.” bilig, no. 69, 2014, ss. 239-262.

Iliadi, Paraskevi, L. Lukeria, and Tatiana V. Larina (2017). "Refusal Strategies in English and Russian. RUDN Journal of Language Studies, Semiotics and Semantics, vol. 8, no. 3, pp. 531-542.

Jalilifar, Alireza. "Request Strategies: Cross-Sectional Study of Iranian EFL Learners and Australian Native Speakers." English Language Teaching, vol. 2, no. 1, 2009, pp. 46-61.

Johanson, Lars. Türkçe Dil İlişkilerinde Yapısal Etkenler. Çev. Nurettin Demir, Türk Dil Kurumu Yayınları, 2007.

Karibayeva, Buadat, ve Salima S. Kunanbayeva. "Kazakh business discourse: Peculiarities of Kazakh business meetings.” PEOPLE: International Journal of Social Sciences, vol. 2, no. 1, 2016, pp. 1455-1462.

Kılınç, Alp Kaan. Yabancı Dil Olarak Türkçe Öğretiminde/Öğreniminde İstek (Rica) 
Söz Edimi. Yüksek Lisans Tezi. Hacettepe Üniversitesi, 2019.

Koike, Dale. "Transfer of Pragmatic Competence and Suggestions in Spanish Foreign Language Learning". Speech Acts Across Cultures: Challenges to Communication in a Second Language, 1996, pp. 257-281.

Koneva, Ekaterina. "The Role of Comparative Analysis in Foreign Language Learning (German and Russian languages).” Procedia-Social and Behavioral Sciences, no. 154, 2014, pp. 319-323.

Kotorova, Elizaveta. "Expressing REQUEST in German and Russian: A Communicative-pragmatic Field Analysis." Procedia-Social and Behavioral Sciences, no. 206, 2015, pp. 36-45.

Littlewood, William, and Baohua Yu. "First Language and Target Language In the Foreign Language Classroom.” Language Teaching, vol. 44, no. 1. 2009, pp. 64-77.

Marti, Leyla. "Indirectness and Politeness in Turkish-German Bilingual and Turkish Monolingual Requests." Journal of Pragmatics, vol. 38, no. 11, 2006, pp. 1836-1869.

Nelson, Gayle L. et al. "Egyptian and American Compliments: A Cross-Cultural Study." International Journal of Intercultural Relations, vol. 17, no. 3, 1993, pp. 293-313.

Ogiermann, Eva. "Politeness and in-directness across cultures: A comparison of English, German, Polish and Russian requests." Journal of Politeness Research, Language, Behaviour, Culture, vol. 5, no. 2, 2009, pp. 189-216.

Özdemir, Azize. Yabancı Dil Olarak Türkçe Öğrenen Öğrencilerin Söz Edimleri Anlama Düzeyleri. Yüksek Lisans Tezi. Hacettepe Üniversitesi, 2016.

Paradowski, Michal B. "Comparative Linguistics and Language Pedagogy: Concise History and Rationale." Multilingualism and Applied Comparative Linguistics: Pedagogical Perspectives, ed. Frank Boers, Jeroen Darquennes ve Rita Temmerman, Cambridge Scholars Publishing, 2007, pp. 1-18.

Polat, Yusuf. Yabancı Dil Öğretiminde Söz Edimleri. Doktora Tezi. Ankara Üniversitesi Sosyal Bilimler Enstitüsü, 2010.

Polat, Yusuf. "Fransızca ve Türkçe Öğretmenlerinin Söz Edimi Öğretimine İlişkin Görüşleri”. Hacettepe Üniversitesi Eğitim Fakültesi Dergisi (H. U. Journal of Education), vol. 30, no. 4, 2015, ss. 146-159.

Sarsenbekova, Gülnur. Kazaklara Türkçe Öğretiminde Yalancı Eş Değer Sözcükler. Yüksek Lisans Tezi. Hacettepe Üniversitesi, 2019. 
Tabar, Mostafa S. "Cross-Cultural Speech Act Realization: The Case of Requests in the Persian and Turkish Speech of Iranian Speakers." International Journal of Business and Social Science, vol. 3, no. 13, 2012, pp. 237-243.

Uğurlu, Mustafa. “Türk Lehçeleri Arasında Kelime Eş Değerliği.” Bilig, no. 29, ss. $29-40$.

Wolfson, Nessa. "Compliments in Cross-Cultural Perspective.” TESOL Quarterly, vol. 15, no. 2, 1981, pp. 117-124.

Yang, Lihong. Speech Act of Request: a Comparative Study of Chinese and American Graduate Students at an American University. PhD Dissertation. Bowling Green State University, 2009.

Yazdanfar, Shiler, and Alireza Bonyadi (2016). "Request Strategies in Everyday Interactions of Persian and English Speakers." SAGE Open, vol. 6, no. 4, pp. 1-11.

Yılmaz, Oğuzhan. "Türkiye Türkçesi Öğrenen Kazakistanlıların Karşılaştıkları Sorunlar”. TÜBAR, no. XXXVII, 2015, ss. 257-275. 


\title{
Teaching Turkish to Kazakhs and a Speech Act Comparison*
}

\author{
Mustafa Durmuş ${ }^{* *}$ \\ Alp Kaan Kılınç***
}

\begin{abstract}
In this study, comparative teaching approach is proposed as a approach that can be used for interdialectal teaching. In this approach, instead of constructing isolated new linguistic or non-linguistic structures related to the target language, it is considered that there will be some benefits of referring to the existing knowledge of the learners: for example, it may facilitate learning, may be useful in error analysis, and may even create more awareness about the target language and its culture. In the face of negative opinions about the problematic of whether the mother tongue has a preventive effect on the learning process of the target language, in this study, it is argued that it actually can be an important support element of the target language when used strategically in addition to the positive effects mentioned above. In this article, the similarities and differences of Kazakh and Turkish speakers in terms of linguistic and cultural elements are pointed out and a comparison example is presented in terms of verbal behaviors. The results of the written study conducted with 20 Turkish and 20 Kazakh university preparatory students were compared with regard to their use of requests. As a result, while some similarities were observed in Turkish and Kazakh students' strategy preferences, various differences were identified, particularly about the use of imperatives and want statements.
\end{abstract}

\section{Keywords}

Teaching Turkish to Kazakhs, teaching Turkish as a foreign language, comparative approach, speech act, request.

\footnotetext{
Date of Arrival: 16 October 2019 - Date of Acceptance: 06 November 2019

You can refer to this article as follows:

Durmuş, Mustafa, ve Alp Kaan Kılınç. "Kazaklara Türkçe Öğretimi ve Söz Edimsel Bir Karşılaştırma." bilig, no. 97, 2021, ss. 1-28.

" Prof. Dr., Hacettepe University, Institute of Turkish Studies - Ankara/Turkey

ORCID ID: https://orcid.org/0000-0002-5337-3113

mustafadurmus@hacettepe.edu.tr

"*. Lecturer, Yildırım Beyazıt University, School of Foreign Languages - Ankara/Turkey

ORCID ID: https://orcid.org/0000-0002-8709-9554

alpkaankilincc@gmail.com
} 


\title{
Преподавание турецкого языка казахам и сравнение речевого акта
}

\author{
Мустафа Дурмуш \\ Алп Каан Кылынч
}

\begin{abstract}
Аннотация
В данном исследовании предлагается сравнительный подход, который может быть использован в междиалектном обучении. В этом подходе вместо создания изолированных новых лингвистических или нелингвистических структур, связанных с целевым языком, считается продуктивным обращение к имеющимся знаниям учащихся: так, это может облегчить обучение, может быть полезным при анализе ошибок и может даже повысить осведомленность о целевом языке и его культуре. Ввиду отрицательного мнения о проблематике того, оказывает ли родной язык профилактическое воздействие на процесс изучения целевого языка, в этом исследовании утверждается, что он на самом деле может быть важным элементом поддержки целевого языка при стратегическом использовании, в дополнение к положительным эффектам, упомянутым выше. В этой статье указаны сходства и различия носителей казахского и турецкого языков с точки зрения лингвистических и культурных элементов, и приведен сравнительный пример с точки зрения речевого поведения. Результаты письменного исследования, проведенного с 20 турецкими и 20 казахскими студентами, готовящимися к поступлению в университет, были сопоставлены с точки зрения использования запросов. В результате, хотя в стратегических предпочтениях турецких и казахских студентов были обнаружены некоторые сходства, были также выявлены различия, особенно в отношении использования императивов и выражении запросов/просьб.
\end{abstract}

\section{Ключевые слова}

Преподавание турецкого языка казахам, преподавание турецкого языкакакиностранного, сравнительныйподход,речевойакт, запрос.

\footnotetext{
Поступило в редакцию: 16 октября 2019 г. - Принято в номер: 06 ноября 2019 г.

Ссылка на статью:

Durmuş, Mustafa, ve Alp Kaan Kılınç. "Kazaklara Türkçe Öğretimi ve Söz Edimsel Bir Karşılaştırma." bilig, no. 97, 2021, ss. 1-28.

** Проф., д-р, Университет Хаджеттепе, Институт тюркских исследований - Анкара / Турция ORCID ID: https://orcid.org/0000-0002-5337-3113 mustafadurmus@hacettepe.edu.tr

*** Преподаватель, Университет Йылдырым Беязыт, Школа иностранных языков - Анкара / Турция ORCID ID: https://orcid.org/0000-0002-8709-9554 alpkaankilincc@gmail.com
} 